\title{
The academic conference evolves: the fMRI Experience
}

\author{
Carl Senior and Peter Reddy \\ Aston University, UK
}

\begin{abstract}
The fMRI Experience began as a postgraduate organised conference, to enable novice access to expertise in a developing and technically complex area, and for mutual support. This paper investigates the seventh annual iteration of this emergent conference and evaluates its educational value. Key features are free attendance supported by sponsorship, a clear focus on student needs and a strong social programme and participation ethos to facilitate interaction. Predominantly qualitative data suggests that the event is of value to postgraduate participants and is also successful in attracting the participation of internationally leading researchers. The implications and value of the event for postgraduate education and for developing new fields of enquiry are discussed.
\end{abstract}

\section{INTRODUCTION}

As technical developments in cognitive neuroscience continue apace it is important that young scientists are given the opportunity to meet both with experts in the field and their peers. Such meetings not only provide opportunities for education but also offer novices support and a sense of participation and belonging. However, such opportunities have been rare. One such is the fMRI Experience, a three-day annual training event created to assist newcomers to cognitive neuroscience and to provide opportunities to meet leading researchers.

It is of interest because it was developed to meet the needs of, and continues to be run by, postgraduate and junior staff, and it has prospered for nine years without either an institutional home or regular support. As a conference designed by students for students it is unusual and it is interesting to investigate how this has happened, if, how and why it works, and what can be learned from it.

\section{What is the fMRI Experience?}

The conference began in 1996 when two postgraduates at the Maudsley Hospital, doubting that any senior staff with fMRI expertise had the time to help them with their data, and feeling the need for access to expertise and mutual support, resolved to obtain both. (A description of $\mathrm{fMRI}$ or functional magnetic resonance imaging is outside the remit of this paper but see Bandettini, 2006). In the summer of 1997 they planned the first fMRI Experience meeting as a small roundtable event and were impressed and alarmed when 105 delegates, mostly postgraduate students, attended. The fMRI Experience has retained its key aim of giving junior researchers access to experts and has evolved strategies to support this. In planning and organisation it is first and foremost a training event with opportunities for junior researchers to discuss their research, meet each other and talk to senior staff.

The social programme is the second key feature of the fMRI Experience. Academic and social events are given equal weight and linked so that participants can move seamlessly from one to the other. The social side of the conference enables junior staff to meet and talk with experts informally in a relaxed environment and helps to attract senior staff who are attending at their own expense and giving their time for free.

Postgraduate students have limited financial support so the third key feature is free registration. As a consequence there is no regular income stream to pay the expenses of keynote speakers or fund room hire, or refreshments, or pay for administration. Considerable effort therefore has to be made to attract sponsorship and it is sponsors' generosity that enables the event to run, as its website $^{2}$ demonstrates. Equivalent conferences of this size (typically 350 delegates) charge fees in the $\$ 400-\$ 1200$ range and the absence of a conference fee enables delegates from far afield (e.g., Australia, China, Iran) as well as from a range of UK universities to attend.

\section{METHOD}

The researchers did not approach the event seeking to establish if it was successful, but to identify what contributed to its apparent success and to consider what could be learned of pedagogic value. An end-ofevent questionnaire was distributed to all delegates. This sought free response to a range of questions and also included 18 Likert-type scales and three semantic differential items (see Table 1). Summary thematic analysis of free response material was undertaken and emerging themes were identified (Boyatzis, 1998). Free response data were read and re-read by both

\footnotetext{
${ }^{1}$ Correspondence for this paper should be addressed to the second author at: School of Life and Health Sciences, Aston University, Birmingham, B4 7ET, UK. Email: p.a.reddy@aston.ac.uk. ${ }^{2}$ See http://www.fmriexp.com/7
} 
researchers independently and emergent themes tentatively identified. Both sets of themes were similar and a composite thematic structure was agreed.

\section{RESULTS AND DISCUSSION}

Fifty-seven questionnaires were returned: 25 from postgraduate and 14 from postdoctoral reseachers, 11 from lecturers, two from undergraduates, two from 'others' and one from an exhibitor. Table 1 summarises the quantitative responses to each of the items in the questionnaire.

All categories of delegate returned questionnaire data that showed some minor areas for change and development for future conferences but no clear pattern of preferences.

Table 1

Qualitative responses to items in the questionnaire

\begin{tabular}{|c|c|c|c|c|c|c|c|}
\hline $\begin{array}{l}\text { (a) Given that more of one thing } \\
\text { means less of another, } \\
\text { would you like?.... }\end{array}$ & More & 1 & 2 & 3 & 4 & 5 & Less \\
\hline Break-out discussion groups & & 11 & 22 & 14 & 3 & 1 & \\
\hline Opportunities to talk to experts & & 15 & 24 & 18 & 0 & 0 & \\
\hline Help with your own research & & 11 & 13 & 24 & 5 & 3 & \\
\hline Help in designing research & & 13 & 15 & 18 & 8 & 2 & \\
\hline Hands-on time with equipment & & 14 & 8 & 23 & 8 & 1 & \\
\hline Informal breaks & & 13 & 15 & 22 & 3 & 3 & \\
\hline Social events & & 4 & 13 & 34 & 4 & 0 & \\
\hline Lectures from leaders in the field & & 17 & 20 & 19 & 0 & 0 & \\
\hline Lectures reporting new research & & 10 & 13 & 28 & 4 & 0 & \\
\hline Lectures reviewing a field & & 17 & 21 & 16 & 2 & 0 & \\
\hline Workshops & & 15 & 13 & 22 & 3 & 5 & \\
\hline Time in labs (collecting data, etc) & & 10 & 11 & 24 & 6 & 4 & \\
\hline Networking time with peers & & 8 & 12 & 30 & 2 & 2 & \\
\hline Time developing skills & & 8 & 7 & 28 & 6 & 6 & \\
\hline Posters & & 6 & 13 & 29 & 5 & 2 & \\
\hline
\end{tabular}

(b) The FMRI experience should develop with an?...

Emphasis on being a conference

Emphasis on being a course

Emphasis on networking \& talking

$\begin{array}{crrrrrr} & 4 & 15 & \mathbf{2 1} & 7 & 3 & \\ & 13 & 22 & 17 & 1 & 3 & \\ & 11 & 16 & \mathbf{1 7} & 8 & 1 & \\ & & & & & & \\ \text { too advanced } & 0 & 9 & 42 & 5 & 1 & \text { too basic } \\ \text { too theoretical } & 3 & 6 & 38 & 4 & 1 & \text { too practical } \\ \text { too intense } & 0 & 8 & 45 & 2 & 0 & \text { too social }\end{array}$

$\begin{array}{crrrrrr} & 4 & 15 & \mathbf{2 1} & 7 & 3 & \\ & 13 & 22 & 17 & 1 & 3 & \\ & 11 & 16 & \mathbf{1 7} & 8 & 1 & \\ \text { too advanced } & 0 & 9 & \mathbf{4 2} & 5 & 1 & \text { too basic } \\ \text { too theoretical } & 3 & 6 & 38 & 4 & 1 & \text { too practical } \\ \text { too intense } & 0 & 8 & \mathbf{4 5} & 2 & 0 & \text { too social }\end{array}$

\section{(c) For me the programme} was?....

Note. The frequency of responses to the three sections of the evaluation questionnaire. Sections (a) and (b) contain the data for 18 Likert-type items where each delegate was asked to indicate how would they want more time to be spent in networking, doing practical work in laboratories or more poster sessions, etc. Section (c) contains three semantic differential items designed to investigate how each delegate generally felt about the meeting. Bold numbers indicate the highest frequency of responses. 


\section{Thematic analysis of delegate responses}

When asked to describe why the conference was different to other events, most delegates commented on the opportunity to socialise and network with peers and experts. Comments such as those below show that newcomers felt the event to be appropriate and useful:

...there is more discussion than other
conferences... (P1)
...It's smaller, more intimate than other
conferences and the organisers really tried to
connect and introduce other people... (P6)

Free registration allowed delegates from a range of countries to attend as well as those from universities without a large research profile that may not have offered much financial support for conference attendance. For example:

...it's a cutting edge meeting design(ed) for students who can attend because it is free registration (P60)

The original diversity of delegates led to the development of a bias towards the cognitive neuroscience newcomer, and questions at all levels and at all sessions are explicitly encouraged.

...it is more informal than other conferences which gives more opportunity for students to ask questions, present their work etc (P3)

...much more exchange with other students... (P2)

Respondent P3 indicated that the bias towards the newcomer was the most important aspect differentiating this from other conferences. This was reiterated by the second delegate (P2). Considering the large number of academic meetings in the cognitive neurosciences, the importance attached to a bias towards the novice suggests that a need exists that is not otherwise addressed. It also suggests that this focus should be visible to delegates, which in turn suggests that it is the delegates themselves that help to develop community affiliation within the student body (Tinto, 1997).

Examination of replies about why the conference was so important shed light on what delegates saw as different about it. Opportunities to meet other students and to network with researchers of equivalent status were important:

...you meet people from all over the world and it's student orientated ... get into contact with others (students and experts)... (P8)

...it gives you the opportunity to talk to other young researchers in my field (P10)

Other comments suggest that the conference offers a boost to research in a number of ways, including learning to use new techniques, generating ideas and getting to grips with the literature:

...it has taught me new techniques to deal with my data and given me new ideas for future research... (P7)

...it allowed me to pick up some bits of information that were extremely useful, but would have taken my ages to have come across in the literature as I wouldn't have been looking directly for it. (P9)

The 'bits of information' mentioned above refer to specific information about research. Such information is likely to be more accessible if received from fellow students who are actually carrying out the research. For some, quite basic information is important:

I'm a user of fMRI, but in my country (Poland) it's still (a) really new method and we have almost no experts in that field. So I had to become an expert in performing fmri, data analysing and everything. It's still very difficult for me so I need more help and some kinds of workshops in this field (P43).

..It's helped give me a more realistic picture of what doing imaging work involves (I have a preclinical background, I thought MEG was like multielectrode electrophysiology before I came!). (P39).

Both these delegates seemed to benefit from the student focus of the conference and from meeting with fellow novices. However the comment below suggests that not all delegates were novices.

... I think people's definitions of beginner vary a lot, I met people who were clearly being pretty bored in the workshop... (P14)

The conference agenda placed social sessions alongside formal didactic sessions and the organisers thought that much science is discussed in these. A large number of delegates noted that social sessions were one of the most important parts of the conference and when asked to indicate what was the most important aspect of the conference comments such as those below reinforce the importance of the social programme:

\footnotetext{
...the social events... (P7)

...networking and talking... (P19)

...networking opportunites [sic]... (P21)

...connections and talks... (P32)

...expert lectures but also the social

programme... (P33)

...meet peers and faculty (the latter could have socialised more with the students). (P16)
} 
The last comment suggests that the social sessions were important and visible and that an opportunity to meet informally with experts is appreciated. Given the importance of networking in psychological research generally and in early career development this may be worth addressing in other conferences. One caveat is that questionnaire items (e.g., "the most valuable part of the programme was...") may have led respondents to reply positively.

A key factor in the success of the fMRI Experience is the willingness of senior staff with successful careers, who are presumably overburdened with demands on their time from students, to attend at their own expense and to give their time freely. Several possible reasons for this apparent academic altruism can be considered.

\section{Proselytising new techniques}

The fMRI Experience came about because of demand from junior staff to understand and use new technology. Its demand led nature perhaps draws down participation from above and is also a response to rapid change. If academic change takes place discontinuously with periods of rapid change alternating with periods of quiescence, and cognitive neuroscience is in a period of development as new technologies are adopted and explored, this may lead initiates to proselytise the new techniques to disciples. This suggests that events such as the fMRI Experience will flourish only in periods of change and that parallels might be found in, for example, the spread of social constructionism and critical social psychology. Certainly the fMRI Experience is presented as a training event to help a new generation of researchers emerge thus encouraging expert participants to feel that they are contributing to the development of the discipline and to developing new talent. Experts are likely to enjoy talking about their areas of interest and expertise and the sense of giving to others for the good of science.

\section{The social programme}

The emphasis on the social programme means that the event is more enjoyable than traditional conferences. It also enables the hothousing of new ideas (the organisers suggest that a number of research ideas and proposals have begun at the fMRI Experience) and functions as an informal employment exchange in bringing together postgraduate and postdoctoral students with senior staff in what began as a small field.

\section{CONCLUSION}

The fMRI Experience was created to serve postgraduate students and its key features-free attendance, emphasis on the social programme, and bias towards the novice-all serve this aim. Taking in hand the limited nature of the evaluation questionnaire that was used in the present study, the data collected suggest that the conference is well adapted to the needs of the core constituency of postgraduate students. The conference may also be an unintentional mechanism that facilitates discussion with researchers outside the immediate peer group.

Results suggest that outside the major postgraduate training centres such as Oxford, London, etc., postgraduate students may benefit from a student focused conference to overcome isolation, raise motivation and enjoy the other benefits mentioned above. There are concerns about postgraduate entry and recruitment in UK higher education and the training conference model outlined here may help to address these. Granted, those wishing to learn about fMRI have to contend with learning the technology, but the fMRI Experience may also hold lessons for the proponents of other novel fields of enquiry, by offering a model of how to develop an academic community from the bottom up and enable student access to heavily oversubscribed experts.

\section{REFERENCES}

Bandettini, P. A. (2006). Functional magnetic resonance imaging. In C. Senior, T. Russell, \& M. S. Gazzaniga (Eds.), Methods in mind (pp. 193-237). Cambridge, MA: MIT Press.

Boyatzis, R. E. (1998). Transforming qualitative information: Thematic analysis and code development. Thousand Oaks, CA: Sage.

Tinto, V. (1997). Classrooms as communities. Journal of Higher Education, 68, 599-623.

Manuscript received on 1 September 2006

Revision accepted for publication on 8 June 2007. 